\title{
Sofrimento psíquico no trabalho e estratégias defensivas dos operários terceirizados da construção civil
}

\author{
Paloma Castro da Rocha Barros ${ }^{1}$ \\ Ana Magnólia Bezerra Mendes ${ }^{2}$
}

\begin{abstract}
Resumo
Este artigo investiga as estratégias defensivas contra o sofrimento utilizadas pelos trabalhadores terceirizados de uma construtora em Brasília, utilizando como referencial teórico-metodológico a Psicodinâmica do Trabalho. Realizam-se entrevistas coletivas semi-estruturadas com 20 trabalhadores, distribuídos em quatro grupos com cinco participantes cada um, submetidas à análise de conteúdo. Os resultados apontam que os trabalhadores encontramse vulneráveis e inseguros diante do modelo de produção terceirizado, que negligencia seus direitos e exige alta produtividade. O sofrimento torna-se visível por meio de indicadores de mal-estar tais como desgaste físico e mental e falta de reconhecimento, que é enfrentado mediante estratégias de mediação defensivas de negação e controle. O pressuposto inicial de que o modelo de produção baseado nos princípios tayloristas e na acumulação flexível de capital, preponderante no setor da construção civil, potencializa o sofrimento no contexto de produção é, então, confirmado.

Palavras-Chave: Construção civil; Psicodinâmica do trabalho; Estratégias de mediação; Sofrimento; Terceirização.
\end{abstract}

\section{Psychic suffering at work and defensive strategies of outsourced worker at building constructions}

\begin{abstract}
This paper investigated defensive strategies to confront suffering used by outsourced workers of building constructions builders in Brasília, having as theoretic-methodological reference the Psychodynamics of Work. Semi structured collective interview were undertaken with 20 workers, distributed in four groups with five participants each one. The interview was submitted to content analysis. The results show the workers presenting vulnerability and insecurity to face outsourced production models that would disregard their rights and demand high productivity. The suffering becomes visible by mal-being symptoms indicated as physic and mental stress and lack of recognition, that is copping by negation and control as defensive mediation strategies. The results confirm the initial presuppositions that the production model based on Taylorist principles and flexible accumulation of capital, predominant at the building construction sector, has a potential to increase suffering at a production context. Keywords: Building constructions; Psychodynamics of work; Mediation strategies; Suffering; Outsourcing.
\end{abstract}

\section{Introdução}

O presente artigo apresenta os resultados de uma pesquisa que visa à investigação das estratégias defensivas para enfrentar o sofrimento utilizadas pelos trabalhadores terceirizados de uma construtora do Distrito Federal, por meio do aporte teóricometodológico da Psicodinâmica do Trabalho. A relevância dessa temática incide sobre a dimensão social, na medida em que corrobora para uma reflexão a respeito das implicações que o modelo de trabalho por produção pode causar à saúde do trabalhador, potencializando o predomínio das vivências de sofrimento, bem como fornece subsídios para se repensar este modelo. As questões norteadoras deste estudo foram: Como se configura o contexto de produção de bens e serviços no qual se inserem estes trabalhadores? Como se caracteriza seu sofrimento? e Quais as estratégias de mediação para se lidar com esse sofrimento?

O processo de globalização, a inserção de novas tecnologias e a reestruturação produtiva têm provocado mudanças significativas no mundo do trabalho como, por exemplo, o surgimento de um novo modelo de produção baseado na acumulação flexível de capital, denominado terceirização. Mattoso (1999) ressalta que a globalização fez desaparecer cerca de 322

${ }^{1}$ União Pioneira de Integração Social (UPIS), Brasília

Endereço para Correspondência:

SCLN 104, bloco D, sala 116, Asa Norte - Brasília-DF - 70733-510

E-mail: palomacastrobarros@hotmail.com

2 Universidade de Brasília 
mil empregos formais, instalando assim a busca por empregos informais e por esse estilo de produção.

As empresas exigem um profissional competente e competitivo, polivalente e criativo, mas nem sempre fornece um suporte organizacional promotor da saúde no trabalho. Diante dessa situação, é visível a distância entre o que a organização espera e prescreve (tarefa) e o que o trabalhador realiza (atividade). Nessa perspectiva, ele é obrigado a utilizar estratégias de mediação a fim de atender às demandas da empresa e manter sua empregabilidade e integridade física e psíquica.

A mediação dessa discrepância entre a tarefa e a atividade implica um custo humano que abarca as dimensões física, psíquica e cognitiva. A incidência dos casos de doenças ocupacionais, tais como DORT, depressão, estresse e Burnout, representa a expressão do sofrimento psíquico vivenciado pelo trabalhador no contexto de produção de bens e serviço, resultado dessa divergência.

Com o intuito de estudar a saúde psíquica no trabalho, a Psicodinâmica do Trabalho privilegia a interrelação entre o sofrimento psíquico, oriundo dos conflitos entre o sujeito e a realidade de trabalho, e as estratégias de mediação empregadas pelos trabalhadores para lidar com o sofrimento e transformar o trabalho em fonte de prazer (Ferreira \& Mendes, no prelo). Este aporte teórico busca analisar as estratégias individuais e coletivas de mediação utilizadas pelos trabalhadores para evitarem o adoecimento e se manterem sadios.

Os três pressupostos que fundamentam esta teoria referem-se ao sujeito como detentor de uma história de vida e participante ativo no processo de construção da subjetividade no trabalho, o que implica uma relação na qual o sujeito, ao mesmo tempo, transforma e é transformado pelo trabalho; ao caráter interdisciplinar que a subsidia teoricamente tendo sua base epistemológica no Existencialismo, na Psicanálise e na Psicossociologia; e a sua origem na Europa do século XIX que contribuiu para o enfoque dos cientistas no movimento operário, a fim de atender às demandas sindicais provenientes das relações entre os trabalhadores, os empregadores e o Estado, bem como à busca de respostas para melhores condições de trabalho e de saúde dos trabalhadores. Com base nesses pressupostos, realizase a pesquisa com os operários da construção civil.

Desde a última década, o setor da construção civil vem passando por um processo de significativas mudanças e reestruturação produtiva em alguns segmentos, o que impacta diretamente na saúde do trabalhador. Essas mudanças contribuíram para o aumento da precarização desse setor, explicitada pela superexploração, por condições de trabalho adversas e insalubres, aumento da jornada de trabalho, desemprego em massa, aumento dos acidentes de trabalho, entre outros fatores.
Nesse setor, a distância entre a tarefa e a atividade torna-se fatal. A primeira se refere às prescrições impostas pela organização ao trabalhador para a operacionalização dos serviços e a segunda está relacionada ao que de fato o trabalhador executa. $\mathrm{O}$ fato de o trabalhador não poder errar, pois isso colocaria em risco a sua vida e a de outras pessoas; ter que fazer o serviço com qualidade, sob o risco de ser despedido ou ser obrigado a refazê-lo e ter que se submeter às precárias condições de trabalho acarreta certa insegurança e vulnerabilidade nesses trabalhadores. Nesse sentido, a utilização de estratégias de mediação passa a ser uma questão de sobrevivência.

Esse ramo caracteriza-se principalmente pela elevada rotatividade e baixo nível de escolaridade dos trabalhadores. Atualmente, pauta-se pela descentralização das atividades e pela descontinuidade do processo produtivo, à medida que os serviços são terceirizados e que o trabalhador não participa de todo o processo de construção da obra (Sousa, 1999).

A empresa reduz custos com os encargos sociais, utilizando um sistema de subcontratação de empresas (vinculadas à cooperativa ou empreiteiras) especializadas em etapas diferentes da obra (fundação, estrutura, alvenaria, entre outras). Essa especialização de serviços reflete o antigo e ainda atual modelo de produção taylorista, baseado na racionalização do trabalho e na cisão entre concepção e execução. Nesse sistema, contratam-se empreiteiros (intermediários entre a empresa e os operários) que se responsabilizarão pelos terceirizados (profissionais autônomos que são contratados temporariamente para a prestação de serviço).

A literatura aponta diversas definições para a terceirização, tais como contrato de trabalho por prazo determinado (Reimann \& Francisco, 1998), forma flexível de contratação (Pinto, 1998), flexibilização das partes contratantes (Silva, 1998), trabalho por produção (Singer, 1998), entre outras. Essa forma de produção tem transformado negativamente as relações trabalhistas, deteriorando os direitos dos trabalhadores.

A terceirização dos serviços, pautada no trabalho por produção e amplamente difundida no ramo da construção civil, tem-se constituído em uma das formas de remuneração geradoras de sofrimento, na medida em que coloca sobre o trabalhador toda a responsabilidade da produção e de sua remuneração. Desse modo, quanto mais produzir, mais ele ganha dinheiro. Essa situação impõe um ritmo acelerado ao trabalhador, fazendo com que ele ultrapasse os próprios limites, o que pode levar ao comprometimento da sua saúde.

Esse modelo de produção, caracterizado pela isenção de vínculo empregatício, negligencia direitos como aposentadoria, INSS, FGTS, plano de saúde, entre outros, submetendo o trabalhador à exclusão 
social. Por essa razão, Reimann e Francisco (1998) apontam a terceirização como causadora de insegurança nas relações trabalhistas, destruidora da identidade coletiva e desmanteladora da cidadania à medida que o trabalhador não consegue construir um modo de vida equilibrado nem fixar-se em uma posição ou classe social como um sujeito permanente.

Não obstante as desvantagens, a questão salarial tem impulsionado os trabalhadores a preferirem este modelo de produção como uma resposta e alternativa ante o desemprego causado pela reestruturação produtiva. Diante disso, os sindicatos tornam-se ineficazes, na medida em que os próprios trabalhadores não têm tempo para lutar e exigir seus direitos, pois nesse contexto "tempo é dinheiro".

Alguns autores (Sousa, 1999; Singer, 1998), ao analisar o processo de trabalho na indústria da construção civil, apontam o trabalho por produção como uma modalidade de exploração do trabalho de forma intensiva, que conduz a um esgotamento físico e mental dos trabalhadores. Nessa perspectiva, Dejours (1999b) ressalta que a pressão socioeconômica de ameaça à perda do posto de trabalho ou dos direitos e garantias trabalhistas tem gerado um sentimento de medo, preponderante nos operários da construção civil, instalando-se assim o sofrimento psíquico.

Ferreira e Mendes (no prelo) definem o sofrimento como uma vivência intensa e duradoura, na maioria das vezes inconsciente, de experiências dolorosas como angústia, medo e insegurança, oriundas do conflito entre necessidades de gratificação do indivíduo e restrição no ambiente de trabalho. Para esses autores, as vivências de sofrimento se originam nas situações adversas provenientes das dimensões da organização, condições e relações de trabalho que estruturam o contexto de produção de bens e serviços. Elas constituem indicadores de mal-estar no trabalho e manifestam-se por meio de sintomas de ansiedade, insatisfação, indignidade, inutilidade, desvalorização e desgaste.

As dimensões do contexto de produção são determinadas por fatores como tarefa, ritmo, tempo e controle do trabalho, ambiente físico, equipamentos e material oferecido pela instituição, bem como as informações disponibilizadas para realização das tarefas, comunicação e sociabilidade entre os pares e a hierarquia. O conjunto desses elementos, ao atuar de forma negativa ou restritiva, é responsável pelo desencadeamento ou não do sofrimento.

Nessa perspectiva, pode-se pressupor que no caso específico da terceirização, dadas as características dessas dimensões, o sofrimento pode ser inevitável por causa da ausência de apoio institucional, pois os trabalhadores têm de "se virar" mediante às situações adversas encontradas no trabalho. Não obstante o sofrimento ressaltado, percebe-se que os trabalhadores conseguem se manter produtivos.

Em face da precariedade das condições de trabalho e ausência de seguridade trabalhista e social, observa-se que a luta pela sobrevivência impulsiona e mobiliza esses trabalhadores a enfrentar o sofrimento por meio da utilização de estratégias de mediação. Diversos autores como Dejours (1987, 1999a, 1999b, 2000), Dejours, Abdoucheli e Jayet (1994), Mendes (1994, 1995, 1996, 1999), Mendes e Linhares (1996), Mendes e Abrahão (1996), Morrone (2001), Ferreira e Mendes (2001, no prelo), Mendes e Tamayo (2001), Mendes, Borges e Ferreira (2002) e Pereira (2003) desenvolveram pesquisas sobre as vivências de prazersofrimento decorrentes do ambiente de trabalho e as formas de enfrentamento do sofrimento.

Dejours (1987) salienta que, para os trabalhadores darem conta do prescrito, corresponderem às expectativas da organização e não adoecerem, eles utilizam estratégias de enfrentamento contra o sofrimento, tais como conformismo, individualismo, negação de perigo, agressividade, passividade, entre outras. De acordo com o autor, a utilização dessas estratégias de defesa propicia proteção do sofrimento e a manutenção do equilíbrio psíquico por possibilitar o enfrentamento e a eufemização das situações causadoras do sofrimento.

Dejours, Abdoucheli e Jayet (1994) consideram as estratégias defensivas, na sua maioria, coletivas. Esses autores definem as estratégias como mecanismos pelos quais o trabalhador busca modificar, transformar e minimizar a percepção da realidade que o faz sofrer. Os autores apontam que a diferença entre um mecanismo de defesa individual e um coletivo está no fato de que o primeiro permanece sem a presença física do objeto, que se encontra interiorizado. Ao passo que o segundo depende da presença de condições externas e se sustenta no consenso de um grupo específico de trabalhadores.

Ao estudar também as defesas e com base nos resultados de diversas pesquisas, Jayet (1994) estabelece categorias de signos indicadores da utilização de estratégias defensivas nas situações de trabalho, os quais devem ser pesquisados na intensidade com que emergem no contexto que envolve o sofrimento, a organização, condições e relações do trabalho. Esses signos isoladamente podem não parecer uma defesa, sendo por isso necessária a contextualização do seu surgimento. Dentre os principais signos apontados pela autora, destacam-se o investimento desproporcional no espaço privado sobre a família e atividades extraprofissionais; a permanente necessidade de se tranqüilizar, evitar conflitos e se reconfortar; a negação da realidade; o ativismo, havendo engajamento em situações múltiplas, evitando-se tomar consciência de determinada situação desagradável; o presenteísmo, 
caracterizado pela presença excessiva no local de trabalho fora do horário regular; a forte coesão das equipes, transformando o agir em uma ideologia; o individualismo, quando realiza tarefas autônomas no próprio grupo, ocorrendo também rupturas no grupo e dispersão das formas de convivência, bem como competição excessiva.

Em suas pesquisas, Mendes (1996) confirma alguns desses indicadores, destacando como antecedentes das defesas as adversidades do modelo de organização do trabalho, que geram um sentimento de impotência dos trabalhadores diante do poder ideológico, econômico, tecnológico e político. Isto paralisa os trabalhadores ante as possibilidades de mudança, restando-lhes a utilização de estratégias defensivas, tais como a racionalização, a passividade e o individualismo.

Segundo a autora, a racionalização é utilizada diante da frustração para explicar de forma lógica os motivos que causam o sofrimento, tais como separação entre planejamento e execução e pela desestruturação das relações psicoafetivas com colegas; o individualismo é uma estratégia utilizada diante do sentimento de impotência e por meio dela os trabalhadores naturalizam o contexto histórico dos fatos que produzem o sofrimento. A passividade é uma estratégia contra o tédio, em função de situações de ameaça de perder o emprego e de manutenção do status quo pela empresa.

Todas essas pesquisas sobre as estratégias defensivas relacionadas ao sofrimento psíquico no trabalho levam a concluir que tais defesas são necessárias para a saúde do trabalhador, embora a condição necessária ao equilíbrio psíquico é ser o trabalho um lugar de prazer, de possibilidade do trabalhador firmar-se enquanto sujeito por meio do reforçamento da sua identidade pessoal e profissional, bem como lugar de reconhecimento, liberdade e valorização do trabalhador. Há sofrimento e defesa como um signo da falibilidade das mediações desenvolvidas para lidar com as contradições do contexto de produção no qual o trabalho é realizado.

Em estudos atuais, Ferreira e Mendes (no prelo) contribuem com a sistematização conceitual das estratégias de mediação do sofrimento psíquico no trabalho, que fundamentam mais especificamente a realização dessa pesquisa. Segundo os autores, para lidar com as vivências de sofrimento oriundas do contexto de produção de bens e serviços, os trabalhadores constroem estratégias de mediação, individuais ou coletivas, contra as situações adversas ao meio, geradoras de sofrimento.

Essas estratégias podem ser de mobilização coletiva ou de defesa. A primeira caracteriza-se pelo modo de agir coletivo dos trabalhadores e tem o objetivo de transformar o contexto de produção e reduzir o custo humano. A mobilização coletiva busca promover o predomínio de vivências de prazer por meio da criação de um espaço público de discussão, construído baseado na cooperação e na confiança mútuas dos trabalhadores no ambiente de trabalho. As estratégias de defesa visam reduzir o custo humano e o sofrimento psíquico no trabalho por meio da utilização de mecanismos de negação e de controle excessivo, que protegem o ego mas podem conduzir à alienação quando utilizados excessivamente.

Nessa perspectiva, os autores afirmam que predomínio da utilização das estratégias de defesa conduz à minimização do sofrimento, mas não à ressignificação e transformação dos aspectos nocivos presentes no contexto de produção, ao passo que a aplicação das estratégias de mobilização coletiva implica redução ou eliminação do sofrimento e mudança da situação de trabalho. Dessa forma, o contexto influencia as estratégias a ser adotadas e que vão prevalecer entre os trabalhadores.

Isso posto, pode-se afirmar que as estratégias de defesa são positivas à medida que protegem o sujeito contra o sofrimento causado pelas situações de trabalho geradoras de conflito, mantendo assim o equilíbrio psíquico e evitando o adoecimento. Em contrapartida, essas defesas tornam-se negativas quando alienam o indivíduo, imobilizando-o. É com base nesse referencial teórico que a pesquisa empírica é realizada, utilizando-se de uma metodologia qualitativa, descrita a seguir.

\section{Método}

\section{Participantes}

A pesquisa realizou-se em uma construtora do Distrito Federal, especificamente em quatro canteiros distintos com estilos gerenciais diferenciados, porém sob o mesmo modelo de produção, qual seja, a terceirização. Participaram deste estudo 20 operários terceirizados, alguns oriundos de empreiteiras e outros vinculados a cooperativas, todos do sexo masculino com idade média entre 30 e 55 anos e baixa escolaridade, variando do ensino fundamental incompleto ao ensino médio incompleto. A amostra foi selecionada pelos dirigentes da construtora com base nos critérios de espontaneidade e disponibilidade de horário dos trabalhadores.

\section{Instrumento}

Como instrumento de coleta de dados foram utilizadas entrevistas coletivas semi-estruturadas realizadas com 4 grupos de 5 trabalhadores. Os temas abordados foram as atividades desenvolvidas, as dificuldades enfrentadas no trabalho e as formas de superá-las, os sentimentos relacionados ao trabalho e as estratégias para lidar com eles, as relações sociais de trabalho (com os pares e chefia) e as condições de trabalho. 


\section{Procedimentos}

As entrevistas foram aplicadas por três entrevistadoras com duração média de 1 hora e meia a duas horas, sendo conduzidas de forma aberta e permitindo-se que os participantes expressassem livremente suas opiniões sobre os temas propostos. Essas temáticas buscaram investigar o contexto de produção de bens e serviços em suas três dimensões, sendo elas a organização do trabalho (divisão do trabalho, produtividade esperada, regras formais e informais, procedimentos e tempo); as condições de trabalho (ambiente físico, instrumentos, equipamentos, matéria-prima, suporte organizacional e política de pessoal); e as relações sociais de trabalho (interações hierárquicas, coletivas e externas), bem como a dinâmica subjacente e as estratégias de mediação utilizadas pelos trabalhadores em face da diversidade das situações de trabalho e das vivências de sofrimento.

\section{Análise dos dados}

As entrevistas foram tratadas qualitativamente por meio da técnica de análise de conteúdo (Bardin, 1977), utilizando-se três juízes para validação interna. As formas de categorização basearam-se nos critérios de recorrência dos temas, extraídos das verbalizações dos próprios trabalhadores.

\section{Resultados e Discussão}

Os resultados obtidos na análise das entrevistas coletivas caracterizam o contexto de produção de bens e serviços por meio das categorias organização, condições e relações sociais de trabalho no setor da construção civil. As categorias descritas apontam para uma organização do trabalho de filiação Taylor-fordista, com fragmentação e padronização das tarefas, controle do ritmo e tempo de trabalho, pressões e sobrecarga, o que possivelmente é um dos elementos potencializadores do sofrimento no trabalho.

As condições de trabalho são precárias e não colaboram com as regras rígidas determinadas pela organização do trabalho (produtividade acelerada), o que implica riscos de acidentes e de aumento do sofrimento pela vivência de sentimentos como ansiedade, medo e insafisfação. As relações sociais de trabalho demonstram que existe um suporte social dado pelos colegas e gestores, o que possivelmente favorece a neutralização do sofrimento advindo da organização e da precariedade das condições de trabalho.

Apresentadas essas categorias antecedentes do sofrimento e das estratégias de mediação, pode-se identificar as categorias referentes aos sentimentos relacionados ao trabalho e às estratégias para suportar essas adversidades. Foram encontradas três categorias, que sintetizam os resultados da análise do conjunto das entrevistas coletivas, sendo elas desgaste físico e mental, falta de reconhecimento e estratégias de mediação para enfrentar o sofrimento.

A categoria desgaste físico e mental demonstra a vivência de sofrimento relacionada ao corpo, que se articula com as exigências cognitivas relativas à preocupação com erros, retrabalho e ritmo, gerando o esgotamento mental. A categoria falta de reconhecimento, manifesta pela insatisfação e descontentamento dos operários, também remete ao sofrimento psíquico.

Identificou-se que diante desse sofrimento os operários utilizam, basicamente, as estratégias do tipo defensivas, de negação e controle da situação geradora de sofrimento. Percebe-se que o sofrimento é pouco verbalizado, mesmo quando falam em cansaço, falta de reconhecimento, tristeza e dor física e moral, pois os trabalhadores encontram formas de justificar tais sentimentos, utilizando o mecanismo de racionalização, expresso em atitudes e comportamentos como explicações lógicas, brincadeiras e necessidade de sobrevivência.

A literatura (Dejours, 1987) aponta que o trabalho pode ser estruturante da identidade do indivíduo, quando a organização valoriza e reconhece o sentido da atividade do trabalhador. Em contrapartida, ele pode ser fonte de sofrimento, quando a atividade não é significativa para o sujeito, para a organização nem para a sociedade.

Parece ser essa a situação dos trabalhadores pesquisados, conforme demonstram as categorias dos resultados das entrevistas. Segundo Dejours (1987), as situações de medo e tédio são responsáveis pela emergência do sofrimento, que se reflete em sintomas como a ansiedade e a insatisfação. $\mathrm{O}$ autor relaciona ainda esses sintomas à incoerência entre o conteúdo da tarefa e as aspirações dos trabalhadores, a desestruturação das relações psicoafetivas com os pares, a despersonalização com o produto e sentimentos de frustração e adormecimento intelectual.

Várias pesquisas foram desenvolvidas para estudar a saúde psíquica e as estratégias de enfrentamento dos trabalhadores ante o sofrimento no contexto de trabalho. Estudos realizados por Mendes (1996) confirmam os achados desta pesquisa, especialmente em relação à organização do trabalho.

Para essa autora, o contexto organizacional pode ser também um fator desestruturante e desestabilizador da saúde psíquica do indivíduo, gerando vivências de sofrimento, à medida que restringe ou extingue a liberdade de expressão de sua individualidade e a tomada de decisão, com base no nãoreconhecimento ou valorização do seu trabalho. Ao contrário, quando a organização do trabalho permite ao trabalhador a expressão da sua individualidade e 
subjetividade, propicia a elaboração e ressignificação do sentido do trabalho, por meio da transformação de situações de desgaste e sofrimento em situações de reconhecimento e prazer.

Por meio de um estudo com operários de fábrica, Daniellou, Laville e Teiger (1989) identificam comportamentos particulares, individuais e/ou coletivos dos trabalhadores para se proteger e se prevenir contra acidentes. Tais comportamentos, como negação do risco, atitude de desafio e resistência à mudança, constituem-se em verdadeiras estratégias de defesa e permitem-lhes enfrentar sua própria ansiedade e/ou a do grupo. Esse tipo de defesa é identificado nos operários pesquisados ao usar as relações sociais para se proteger de acidentes e as brincadeiras como forma de aliviar a ansiedade.

Outros comportamentos defensivos apontados por Jayet (1994) são observados nos operários pesquisados, tais como investimento no espaço privado sobre a família e atividades extraprofissionais; evitação de conflitos e necessidades permanentes de tranqüilidade e reconforto; negação da realidade; engajamento em múltiplas atividades numa tentativa de evitação às situações desagradáveis; e forte coesão do grupo, transformando o agir em ideologia.

A utilização de estratégias defensivas por parte desses operários pode ser considerada positiva à medida que minimiza o sofrimento causado pelas situações de trabalho geradoras de conflito, favorecendo assim o equilíbrio psíquico. Porém, esta utilização pode ser negativa quando provoca uma estabilidade psíquica artificial, alienando o indivíduo e não provocando mudanças no contexto de trabalho.

A vivência de sofrimento desses operários caracterizada nas categorias desgaste físico e mental, falta de reconhecimento e estratégias de enfrentamento, bem como as dimensões da organização, condições e relações sociais de trabalho têm fundamento nos estudos de Dejours (1999a, 1999b, 2000), que considera as atuais mudanças no mundo do trabalho como responsáveis pela sobrecarga elevada, associada à exigência pelo aumento de produtividade, o que torna o sofrimento inevitável. Segundo o autor, o sofrimento tem origem na mecanização e robotização das tarefas, nas pressões e imposições da organização do trabalho, refletindo no trabalhador um sentimento de incapacidade $\mathrm{e}$ incompetência diante dessa realidade.

Identifica-se nos resultados das entrevistas dos trabalhadores pesquisados uma pressão imposta pela empresa em ter que se produzir a todo custo, muitas vezes sem condições físicas, ambientais e psicológicas adequadas de trabalho, obrigando o trabalhador a desenvolver estratégias de mediação a fim de atender às demandas da empresa, o que causa a ele um sofrimento psíquico. Nesse sentido, parece que a atual forma de organização do trabalho tem gerado a incidência de vivências de sofrimento no contexto de produção de bens e serviços em razão da rigidez e da falta de liberdade no trabalho.

Nessa perspectiva, os resultados desta pesquisa confirmam os estudos da Psicodinâmica do Trabalho, que apontam a organização do trabalho como o principal fator de desencadeamento do sofrimento, conforme pesquisas empíricas de Ferreira e Mendes (2001); Mendes e Tamayo (2001); Mendes (1999); Mendes e Abrahão (1996). Tais pesquisas constatam que as vivências de sofrimento estão associadas à divisão e à padronização de tarefas, com perda do potencial humano e da criatividade; rigidez hierárquica, com excesso de procedimentos burocráticos; ingerências políticas; centralização de informações; falta de participação nas decisões e não-reconhecimento, além de pouca perspectiva de crescimento profissional.

Percebe-se que esses operários estão submetidos a uma organização do trabalho rígida, expressa por princípios tayloristas, a condições de trabalho precárias e ao sofrimento. Esse sofrimento está especificamente relacionado à exigência da empresa por qualidade, extrema precisão e perfeição das atividades, não admitindo qualquer erro dos trabalhadores, que são punidos com o retrabalho na ocorrência de mínimas falhas, além de arcar com o prejuízo de desmanchar e refazer sem ganhar por isso. Diante disso, os trabalhadores são obrigados a reprimir o sofrimento decorrente do controle e das pressões, não podendo reclamar desse sofrimento para não perder a vaga na empresa.

Somam-se a esse sofrimento as condições precárias e subumanas nas quais esses trabalhadores desenvolvem suas atividades, evidenciadas na alimentação e alojamento inadequados, insuficientes e precários. Observa-se também a ausência de amparo trabalhista e social, expressa pela negação de direitos básicos como aposentadoria, plano de saúde, entre outros. Além disso, a falta de apoio institucional quanto ao fornecimento de ferramentas essenciais para o desenvolvimento do trabalho e de equipamentos de segurança (EPIs) caracteriza a desproteção dos trabalhadores terceirizados dessa categoria quanto à ocorrência de acidentes no trabalho.

As relações sociais de trabalho parecem minimizar o sofrimento vivenciado pelos trabalhadores e fazem-nos continuar a produzir. A coesão do grupo e o relacionamento satisfatório com a chefia demonstram ser os indicadores da manutenção do equilíbrio psíquico dos trabalhadores pesquisados. Para enfrentar as adversidades do contexto de produção e atender às demandas da empresa, esses trabalhadores recorrem ao empréstimo entre si de materiais, ferramentas e 
equipamentos de segurança, tendo em vista a precariedade do suporte organizacional.

Diante desse sofrimento, constata-se que os trabalhadores utilizam estratégias defensivas de negação e controle a fim de enfrentá-lo, demonstradas nos resultados das categorias desgaste físico e mental e falta de reconhecimento. Identifica-se que para enfrentar a exaustão física eles procuram descansar à noite, a fim de se recuperar para o dia seguinte; quanto ao esgotamento mental, eles permanecem em estado de alerta para evitar erros, e assim não ter prejuízos. A produtividade durante o dia parece amenizar os efeitos desgastantes de um dia de trabalho, de forma que, quando conseguem produzir muito, eles terminam o dia alegres, esquecendo-se do cansaço físico e mental, ao passo que quando isso não ocorre, por causa da falta ou do atraso de material, eles finalizam o dia pensando que não valeu a pena todo o cansaço.

A categoria falta de reconhecimento aponta que a maioria dos trabalhadores não se sente reconhecida no trabalho pela chefia imediata (encarregado) quando é obrigada a desmanchar e refazer o trabalho, nem pela empresa quando o seu nome não aparece no final da construção. Os trabalhadores que se sentem reconhecidos percebem o reconhecimento quando o ex-encarregado os procura para voltarem a trabalhar juntos ou quando o encarregado não confere o serviço por confiar no trabalho do operário. Eles se sentem ainda reconhecidos quando, às vezes, a empresa dá uma pequena festa ao término das obras.

Os trabalhadores da construção civil enfrentam o sofrimento por meio de brincadeiras, canções e conversas, que são compartilhadas entre o grupo. Quando estão sozinhos, eles pensam na família, mulher, filhos, dívidas e planos para o futuro como estratégia para amenizar o sofrimento, fazendo "passar o tempo" e o serviço "render mais". Identifica-se ainda que esses trabalhadores utilizam uma outra estratégia de defesa de negação quando não pensam em nada, nem no trabalho, nem em outros assuntos, executando o trabalho mecanicamente, como uma forma de alienação.

Isso posto, as perguntas norteadoras do estudo são respondidas na direção de confirmar uma vivência de sofrimento, com as características acima descritas, influenciada pelo contexto de produção ao qual estão submetidos esses trabalhadores e que reflete as problemáticas da terceirização. Esse sofrimento é mediado pelo uso de defesa, que exerce papel de proteção contra os afetos dolorosos advindos das adversidades do trabalho, mas pode também funcionar como um sinal de alerta para a saúde psíquica desses operários, considerando que a intensidade do uso de defesa pode levar a seu fracasso e, conseqüentemente, ao adoecimento.

\section{Conclusão}

Com base nos resultados do presente estudo, pode-se considerar que a terceirização, baseada nas premissas do modelo de produção Taylor-fordista, potencializa as vivências de sofrimento nos trabalhadores inseridos no contexto de produção de bens e serviços. O sofrimento é enfrentado por meio da utilização de estratégias de mediação do tipo defensivas de negação e controle excessivo como medida de redução do custo humano no trabalho e, conseqüentemente, o sofrimento.

Esta pesquisa contribui para a discussão das questões de saúde no trabalho na medida em que dá visibilidade ao sofrimento psíquico dessa categoria, subsidiando, assim, uma reflexão sobre o modelo de produção terceirizado, a fim de se repensar o processo de trabalho como fonte e lócus de prazer, e não de sofrimento. Pode-se salientar também a contribuição para o questionamento e a otimização das políticas gerenciais vigentes e a relevância do suporte organizacional como minimizador do sofrimento psíquico dos trabalhadores. Além disso, este estudo colabora para o enriquecimento da literatura na perspectiva teóricometodológica da Psicodinâmica do Trabalho.

Não obstante as contribuições, algumas limitações da pesquisa devem ser reconhecidas, tais como, foram estudados operários terceirizados de apenas uma empresa; há necessidade de investigação mais aprofundada das características das estratégias de mediação; não se trata de um estudo comparativo entre operários terceirizados e registrados na construção civil. Dessa forma, esta pesquisa abre novas perspectivas para futuras investigações, sugerindo-se, então, o desenvolvimento de outros estudos para investigar quantitativamente a intensidade do sofrimento desses profissionais, cotejar a incidência de sofrimento dos operários registrados e dos terceirizados, e ampliar a investigação das estratégias de mediação para outras categorias profissionais submetidas a diferentes contextos de produção, o que contribuiria assim para o avanço e fortalecimento do conhecimento nas áreas de saúde mental e do trabalho na abordagem da Psicodinâmica do Trabalho.

\section{Referências}

Bardin, L. (1977). Análise de conteúdo. Lisboa: Edições 70.

Daniellou, F., Laville, A. \& Teiger, C. (1989). Ficção e realidade do trabalho operário. Revista Brasileira de Saúde Ocupacional, 17(68), 70-84.

Dejours, C. (1987). A loucura do trabalho: estudo de psicopatologia do trabalho. São Paulo: Cortez.

Dejours, C. (1999a). O fator humano. Rio de Janeiro: Editora FGV. 
Dejours, C. (1999b). Conferências brasileiras: identidade, reconbecimento e transgressão no trabalho. São Paulo: FUNDAP.

Dejours, C. (2000). A banalização da injustiça social. Rio de Janeiro: Editora FGV.

Dejours, C., Abdoucheli, E. \& Jayet, C. (1994). Psicodinâmica do trabalbo: contribuiçôes da escola dejouriana à análise da relação prazer, sofrimento e trabalho. São Paulo: Atlas.

Ferreira, M. C. \& Mendes, A. M. (2001). "Só de pensar em vir trabalhar, já fico de mau humor": atividade de atendimento ao público e prazer-sofrimento no trabalho. Revista Estudos de Psicologia, 6 (1), 97-108.

Ferreira, M. C. \& Mendes, A. M. (no prelo). Trabalho dos AFPS e indices de adoecimento: estado de alerta. Brasília: Fenafisp.

Jayet, C. (1994). Psychodynamique du travail au quotidien. Paris: AleXitére.

Mattoso, J. (1999). O Brasil desempregado: como foram destruídos mais de 3 milhões de empregos nos anos 90. São Paulo: Editora Fundação Perseu Abramo.

Mendes, A. M. (1994). Prazer e sofrimento no trabalho qualificado: um estudo exploratório com engenheiros de uma empresa pública de tecomunicações. (Dissertação de Mestrado). Brasília: Universidade de Brasília.

Mendes, A. M. (1995). Os novos paradigmas de organização do trabalho: implicações na saúde mental dos trabalhadores. Revista Brasileira de Saúde Ocupacional, 23 (85/86), 55-60.

Mendes, A. M. (1996). Comportamento defensivo: uma estratégia para suportar o sofrimento no trabalho. Revista de Psicologia, 13/14 (1/2), 27-32.

Mendes, A. M. (1999). Valores e vivências de prazersofrimento no contexto organizacional. (Tese de Doutorado). Brasília: Universidade de Brasília.

Mendes, A. M. \& Abrahão, J. L. (1996). A influência da organização do trabalho nas vivências de prazer-sofrimento do trabalhador: uma abordagem psicodinâmica. Revista de Psicologia: Teoria e Pesquisa, 26(2), 179-184.
Mendes, A. M. \& Linhares, N. J. R. (1996). A defesa como uma estratégia frente ao sofrimento no trabalho: um estudo com enfermeiros de UTI. Revista Brasileira de Enfermagem, 49(2), 267-280.

Mendes, A. M. \& Tamayo, A. (2001). Valores e vivências de prazer-sofrimento no contexto organizacional. Psico-USF, 6(1), 39-46.

Mendes, A. M., Borges, L. O. \& Ferreira, M. C. (2002). Trabalho em transição, saúde em risco. Brasília: Universidade de Brasília.

Morrone, C. F. (2001). "Só para não ficar desempregado". Ressignificando o sofrimento psíquico no trabalho: estudo com trabalhadores em atividades informais. (Dissertação de Mestrado). Brasília: Universidade de Brasília.

Pereira, J. A. S. (2003). Vivências de pražer e sofrimento na atividade gerencial em empresa estratégica: o impacto dos valores organizacionais. (Dissertação de Mestrado). Brasília: Universidade de Brasília.

Pinto, J. A. R. (1998). O direito do trabalho e as questões do nosso tempo. Em L. Reimann e M. Francisco (Orgs.). Cidadania e contratos atípicos de trabalho. Porto Alegre: Sergio Antônio Fabris Ed.

Reimann, L. \& Francisco, M. (Org.). (1998). Cidadania e contratos atípicos de trabalho. Porto Alegre: Sérgio Antônio Frabris Ed.

Silva, R. P. (1998). O neoliberalismo e o discurso da flexibilidade dos direitos sociais relativos ao trabalho. Em J. E. L. Arruda \& A. Ramos (Org.). (pp. 63-94). Globalização, neoliberalismo e mundo do trabalho. Curitiba: IBEJ.

Singer, P. (1998). Globalização e desemprego - diagnóstico e alternativas. São Paulo: Contexto.

Sousa, N. H. Bicalho de (1999). Gestão do trabalho na indústria da construção civil: práticas tradicionais e perspectivas futuras. Ser Social, 5, 159-188.

Enviado em abril de 2003

Reformulado em junho de 2003

Aprovado em junho de 2003

Sobre as autoras:

Paloma Castro da Rocha Barros é psicóloga organizacional, professora nos Departamentos de Administração e de Hotelaria da União Pioneira de Integração Social (UPIS), Brasília-DF.

Ana Magnólia Bezerra Mendes é doutora em Psicologia Social e do Trabalho pela Universidade de Brasília, professora do Departamento de Psicologia Social e do Trabalho do Instituto de Psicologia da Universidade de Brasília. 